$r$

e

S

e

ก

a

S 



\title{
Paisajes de varones. Genealogías del homoerotismo en la literatura argentina. Jorge Luis Peralta. Barcelona: Icaria, 2017. ISBN: 978-84-9888-753-2. 190 pp.
}

\author{
Por Andrés Ibarra Cordero \\ Universiteit van Amsterdam \\ a.ibarracordero@uva.nl
}

El pasado y sus espacios pueden revelar mucho acerca de cómo habitamos y experimentamos nuestro presente. Esta es la premisa base de Paisajes de varones. Genealogías del homoerotismo en la literatura argentina, el fascinante ensayo del investigador y académico Jorge Luis Peralta. Este trabajo propone un acabado análisis de textos literarios como una lucha discursiva en donde los deseos homoeróticos masculinos crean espacios propios. A diferencia de otros trabajos dedicados a la diversidad sexual en todas sus manifestaciones, el libro de Peralta se enfoca exclusivamente en un canon homoerótico de "varones", como señala el título. Lo anterior no obedece a un protocolo patriarcal, sino al hecho que los hombres suelen gozar de los privilegios que otorga la hegemonía masculina. Así, la lectura y reflexión del autor enfatizan que aun cuando ciertos hombres no se amolden a una sexualidad normativa, ellos no dejan de disfrutar de un acceso favorable a la esfera pública. Por otra parte, las mujeres que se relacionan eróticamente con otras mujeres, sufren una doble exclusión. Por esta razón, argumenta el autor, los espacios homoeróticos femeninos son con frecuencia de carácter privado o doméstico.

Peralta aborda la representación literaria de ciertos espacios homoeróticos en donde el deseo se encuentra ligado a contextos netamente homosociales, y cómo estos textos elaboran la construcción de dichos temas. El espacio, de esta forma, no significa un simple lugar en donde ocurren los eventos, sino un conector elocuente de subjetividades y deseos abyectos. Paisajes de varones ofrece

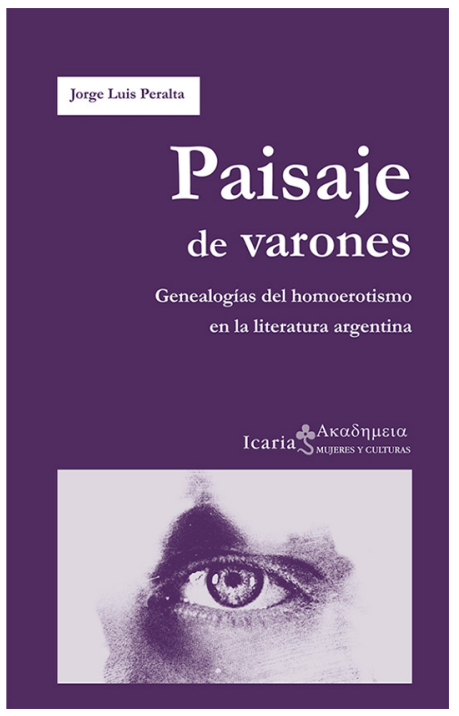


una valiosa lectura que evidencia las construcciones de espacios y deseos homoeróticos, a la vez que se teoriza cómo dichos espacios se inscriben en la producción literaria, desde la segunda mitad del siglo XIX hasta la década de 1950. La elaboración de un espacio propio del homoerotismo argentino se convierte en objetivo final dentro del discurso que analiza el académico.

El análisis textual de Peralta aborda una amplia gama de obras literarias (incluyendo narrativa y drama), escritas o publicadas en Argentina, anteriores a la década de 1950, período en el que se consolida en definitiva la literatura homoerótica. Según el autor, la literatura homoerótica argentina tiene una larga tradición, aun cuando se potencie a partir de 1950 , por medio de autores como Renato Pellegrini y Carlos Correas. Sin embargo, este nuevo escenario de representación del homoerotismo masculino no significó un fenómeno sin precedentes o aislado. Por el contrario, solo fue el resultado de un largo proceso; por medio de este espacio y deseo se articularon de diversas formas, anticipando muchas veces la escena literaria de 1950. En definitiva, el surgimiento de un nuevo paradigma de representación del homoerotismo se debe comprender como resultado de un extenso recorrido.

Al indagar en cuál fue el aporte de obras anteriores a 1950 a la conformación de una espacialidad homoerótica, Peralta analiza las construcciones de esa espacialidad como resultado de cronotopos específicos que contribuyen a su respectiva interpretación. Desde El matadero (1839), de Esteban Echeverría, hasta El retrato amarillo (1956), de Manuel Mujica Láinez, esta investigación examina representaciones espaciales vinculadas a contextos socioculturales específicos. El análisis textual se beneficia de perspectivas historiográficas con el propósito de esclarecer los contextos sucesivos en que emergieron las obras seleccionadas y su incidencia en la representación de espacios homoeróticos.

El ensayo propone una lectura y reflexión en torno a las complejas configuraciones literarias del deseo homoerótico, las que están sujetas a contextos históricos y socioculturales muy dinámicos, en donde los límites de lo "respetable" se fueron transformando paulatinamente por medio de los años. Sin embargo, Paisaje de varones no constituye un intento de "historizar" las representaciones literarias del espacio homoerótico. Es más bien un intento de desvelar en qué forma esas representaciones, vinculadas a realidades concretas, dan cuenta de ellas, ya sea respetando sus normas o transgrediéndolas, con distintos grados de intensidad. En consecuencia, Peralta nos ofrece un análisis "genealógico" de los discursos en torno a los espacios del homoerotismo.

A diferencia de muchos trabajos en torno al género, que suelen seguir una clara agenda política pero no metodológica, la investigación de Peralta ofrece una contundente justificación de su enfoque teórico y metodológico. Este ve, por ejemplo, el "espacio homoerótico" como un producto social en constante recreación y vivenciado en sus circunstancias históricas concretas (22). Al enfocarse en las obras literarias anteriores a la formación de una literatura homoerótica más acabada, el autor se propone rescatar producciones literarias que distan de los textos que se observan en la producción reciente. Este homoerotismo encriptado contiene un 
paradigma conceptual que también puede revelar textos más recientes, proporcionando una ruta en donde las disidencias sexuales existieron y dejaron una huella testimonial en la literatura argentina. El ensayo refuerza la idea de que las obras analizadas no están desconectadas de su contexto sociocultural; textos y contextos se entrelazan continuamente.

Paisaje de varones sigue coordenadas espacio-temporales específicas y se inclina por indagar en un campo rara vez visitado por los estudios gais, lésbicos y queer argentinos; y menos aún por los estudios literarios en la academia. Peralta vuelve a la idea de que El beso de la mujer araña (1976) de Manuel Puig habría marcado un punto de ruptura en la representación literaria de la homosexualidad masculina, ya que esta supone la idea errada de que anteriormente no existieron configuraciones textuales del deseo homoerótico o que estas estuvieron vinculadas a imágenes estigmatizantes o negativas. Para el autor, la novela de Puig fue pionera en articular un nuevo discurso acerca de la homosexualidad debido a un contexto mucho más propicio a esa problematización discursiva y política. Sin embargo, esto no significó la ausencia de literatura homoerótica anterior a la novela de Puig.

Este trabajo es adecuado y cauto al usar un léxico pertinente a las características de cada momento histórico. Se tiene en consideración las maneras en que estas subjetividades fueron definidas desde instancias normativas (por ejemplo: la medicina, la psiquiatría o la ley), y también cómo estas se definieron a sí mismas. La fluctuación de los términos léxicos y de las realidades sexuales, afectivas y sociales que describen constituye la base indiscutible para precisar el significado de los términos usados. Palabras frecuentes en este ensayo, como el adjetivo "homoerótico" y el sustantivo "homoerotismo," son usadas con mucha conveniencia, debido a que no conllevan adscripciones identitarias. En general, estos términos evitan el riesgo de reflexionar respecto de realidades sociosexuales del pasado con conceptos elaborados en forma posterior, y se amoldan al objetivo de la investigación y de su lectura atenta a las significaciones inestables del género y la sexualidad en el acontecer histórico. Por consiguiente, Peralta opta por el término "homoerótico" a "homosexual" o "gay" debido a que su uso, según Félix Rodríguez González, se refiere a "prácticas sexuales entre personas del mismo sexo que no suponen la construcción de una identidad determinada" (en Peralta 11).

Siguiendo la línea trazada por investigaciones historiográficas recientes (Ben 2009; Acha 2014), Paisaje de varones reafirma la tesis de que la identidad homosexual no se habría constituido en Argentina hasta entrada la década de 1950. Por otra parte, el modelo gay se consolidó entre las décadas de 1980 y 1990 (Sívori 2004; Meccia 2011). Por esta razón, Peralta argumenta que resultaría anacrónico referirse a un espacio "homosexual" o "gay" en tiempos en que estos términos identitarios no se habían consolidado. Al carecer la variedad de connotaciones que se le atribuyen a las identidades "homosexuales" y "gays", lo "homoerótico" es propuesto como un concepto propicio para referirse a los hombres que se relacionan eróticamente con otros hombres. El autor descarta, de igual 
forma, el uso de queer, abundante en la bibliografía anglófona referente a este tema, debido a su distancia con el espacio y el periodo histórico examinados en esta investigación.

Las genealogías literarias propuestas son tres: territorios esquivos, mapas fundacionales y homotextualidades. Estas genealogías proponen aportes heterogéneos a una espacialidad homoerótica que la literatura posterior continuó - como lo fue en el caso de la narrativa de temática gay urbana-o abandonó - como la escritura homotextual- debido a que en contextos más liberales ya no fueron necesarias aquellas codificaciones propias a esa tradición. En el capítulo II, "Territorios esquivos", se revisan algunos ejemplos en los que se vislumbran territorios potencialmente homoeróticos, aunque su aporte no registra la misma importancia que la literatura posterior. Desde el relato fundacional El matadero (1839), de Esteban Echeverría, a los cuentos fantásticos en Las fuerzas extrañas (1906) de Leopoldo Lugones, Peralta observa incursiones preliminares en una espacialidad que, a partir de Los invertidos, comienza a ganar forma y a ser objeto de representaciones cada vez más acabadas. Estas son algunas de esas obras que muestran territorios "esquivos", es decir, espacios que sugieren una alteridad sexual (36). En el capítulo III, "Mapas fundacionales", Peralta se enfoca en textos que contribuyen a una espacialidad ligada a poblaciones eróticas disidentes. El texto dramático Los invertidos, de González Castillo, sella el inicio de una breve genealogía que continúa con textos narrativos de la década de 1920: el cuento "Riverita" (1925) de Roberto Mariani y un fragmento de la novela El juguete rabioso (1926) de Roberto Arlt. Finalmente, esta genealogía es cerrada con la novela de Bernardo Kordon Reina del Plata (1946).

Lo anterior resulta simbólico de una transformación de la sociabilidad homosexual, como podrá constatarse mediante la revisión de algunos estudios historiográficos que apoya el análisis textual. La progresiva diferenciación de los "homosexuales" como un grupo marginal marca la consolidación de una subcultura con formas de apropiación espacial igualmente diversas. El capítulo IV funciona como una pausa en donde Peralta abandona las representaciones espaciales que poseen una relación directa con la "realidad" para abordar obras en donde la espacialidad se configura en una esfera "textual". Aquí, si bien pueden existir vínculos con espacios reales, estos son primordialmente retóricos. Partiendo del concepto de "homotextualidad" propuesto por Stockinger (1978) y elaborado entre otros por el español Martínez Expósito (1998), Peralta analiza varios textos en los que el deseo homoerótico se configura por medio de distintos códigos discursivos, algunas veces reconocibles como propios de esta tradición literaria. Estos espacios retóricos son propuestos como la fase precedente a la espacialización explícita que llega a imponerse a partir de 1950. Peralta comprende la literatura homotextual como un puente hacia nuevas formas textuales en donde se articula una nueva expresión del deseo homoerótico. Al comparar las obras, Álamos talados (1942) de Abelardo Arias, Sombras suele vestir (1941), Las ratas (1943) de José Bianco, y El retrato amarillo (1956) de Manuel Mujica Láinez, se observa cómo estos textos articulan un "espacio retórico" mediante un discurso en donde predominan la ambigüedad y las alusiones. 
Finalmente, el surgimiento de una subcultura cuyos individuos se identifican a sí mismos como "homosexuales" tiene un impacto tanto en la vida diaria como en la ficción. Sin embargo, las versiones literarias de espacios reales en los que el homoerotismo se manifiesta difieren mucho de ofrecer una mirada uniforme. En vez de seguir una coordenada de carácter histórico, el autor ofrece una directriz genealógica que estructura una variedad de textos que obedecen a una lógica espacial. Por otra parte, más que proponer un estudio relativo a la producción literaria que aborda la representación del homoerotismo en sí, el ensayo aborda la constitución del espacio como un concepto eje para comprender la articulación del homoerotismo en estos mismos.

El trabajo de Peralta se propone iluminar textos y espacios, combatiendo el silencio al que han sido sometidos, la omnipresencia de la heteronormatividad, el olvido de la memoria o la simple apatía hacia esas "locas de antaño" (147). Debido a que algunos textos funcionan como "portadores oficiales de los modelos canónicos del mundo" y sirven para "mantener el orden social y político" (33), esta investigación desafía ese eje programático y propone maneras de actuar que contradicen ese poder hegemónico. Muchos de estos textos que fueron considerados marginales debido a sus identidades y prácticas sexuales, tuvieron el desafío de crear un espacio, tanto en la vida cotidiana como en la producción cultural. Por consiguiente, Paisaje de varones no solo es un valioso recorrido genealógico que se nutre de obras literarias como documentos de carácter histórico, sino también como material orgánico capaces de articular posibles utopías literarias para la disidencia sexual. Es, en cierta forma, un gesto reivindicativo que valida las luchas que han sido inscritas en lo espacial y que continúan siendo una batalla continua.

\section{Obras citadas}

Acha, Omar. Crónica sentimental de la Argentina peronista. Sexo, inconsciente e ideología, 1945-1955. Buenos Aires: Prometeo, 2014.

Ben, Pablo. Male Sexuality, the Popular Classes and the State: Buenos Aires, 18801955. Tesis doctoral. Chicago: University of Chicago, 2009.

Martínez Expósito, Alfredo. Los escribas furiosos. Configuraciones homoeróticas en la narrativa española actual. Nueva Orleans: University Press of the South, 1998.

Meccia, Ernesto. Los últimos homosexuales. Sociología de la homosexualidad y de la gaycidad. Buenos Aires: Gran Aldea, 2011.

Rodríguez González, Félix. Diccionario gay-lésbico. Vocabulario general y argot de la homosexualidad. Madrid: Gredos, 2008.

Sívori, Horacio. Locas, chongos y gays. Sociabilidad homosexual masculina durante la década de 1990. Buenos Aires: Antropofagia, 2004.

Stockinger, Jacob. "Homotextuality: A Proposal." The Gay Academic. Ed. Louie Crew y Ellen Barrec, ETC, Palm Springs, 1978, pp. 135-151. 
